\title{
PENGARUH PEMAHAMAN WAJIB PAJAK, KESADARAN WAJIB PAJAK, DAN PELAYANAN FISKUS TERHADAP KEPATUHAN WAJIB PAJAK BUMI DAN BANGUNAN
}

\author{
Imam Oktafiyanto $^{1}$, Dewi Kusuma Wardani ${ }^{2}$
}

\begin{abstract}
The purpose of this study was to determine the affect of understanding the taxpayer, the taxpayer awareness, and services tax authorities on tax compliance and building earth. This research was conducted in the Department of Regional Tax and Financial Management of Yogyakarta. Data Collected by using a questionnaire. Tecnical analysis of the data used is multiple linier regression technique. Based on the analysis that has beeb done, it can be seen that the understanding of the taxpayer, the taxpayer awarenness, and service tax authoroties on tax compliance affect the land and building.
\end{abstract}

Keywords: Understanding taxpayer, taxpayer Awareness, Service tax authorities and Taxpayer Compliance.

\footnotetext{
${ }^{1}$ Alumni Program Studi Akuntansi Fakultas Ekonomi Universitas Sarjanawiyata Tamansisw Yogyakarta

${ }^{2}$ Dosen Program Studi Akuntansi Fakultas Ekonomi Universitas Sar
} 


\section{Pendahuluan}

Pajak sebagaimana yang diketahui merupakan aspek penting bagi kelangsungan hidup negara Indonesia. Dalam menjalankan pemerintahan dan pembangunan, pemerintah membutuhkan dana yang tidak sedikit. Sebagai salah satu unsur penerimaan negara, pajak memiliki peran yang sangat besar dan semakin diandalkan untuk kepentingan pembangunan dan membiayai pengeluaran pemerintah. Pada APBN 2011, pajak memberikan kontribusi sebesar Rp827.264,2 milyar sedangkan pada APBN 2012, penerimaan pajak meningkat dari tahun 2011 menjadi Rp1.032,6 triliun (www.fiskal.depkeu.go.id). Pajak adalah iuran rakyat kepada kas negara berdasarkan undang-undang (yang dapat dipaksakan) dengan tidak mendapat jasa timbal, yang langsung dapat ditunjukkan dan yang digunakan untuk membayar pengeluaran umum (Suandy, 2005).

Pajak daerah merupakan pajak yang dikelola oleh pemerintah daerah baik provinsi maupun kabupaten atau kota yang berguna untuk menunjang penerimaan pendapatan asli daerah. Pajak daerah sebagai salah satu kegiatan pemerintah berkaitan dengan pengelolaan keuangan daerah mempunyai tujuan untuk meningkatkan kesejahteraan masyarakat. Dasar dilakukanya pemungutan oleh pemerintah daerah adalah Undang-
Undang No.25 Tahun 1999 tentang Otonomi Daerah yang mengatakan bahwa pemerintah dan masyarakat dipersilakan mengurus rumah tangganya sendiri secara bertanggung jawab.

Salah satu pajak yang menjadi potensi sumber pendapatan daerah yaitu Pajak Bumi dan Bangunan (PBB). Sejak tahun 2011 penarikan Pajak Bumi dan Bangunan (PBB) dilimpahkan dari Pemerintah Pusat ke Pemerintah Kota sesuai dengan Peraturan Bersama Menteri Keuangan dan Menteri Dalam Negeri Nomor: 213/PMK.07/2010, Nomor: 58 Tahun 2010 tentang Tahapan Persiapan Pengalihan Pajak Bumi dan Bangunan Perdesaan dan Perkotaan sebagai Pajak Daerah.

Pajak Bumi dan Bangunan (PBB) merupakan iuran yang dikenakan terhadap orang atau badan yang secara nyata mempunyai hak, memiliki, menguasai dan memperoleh manfaat dari bumi dan bangunan (Rahman, 2011). Pemerintah Kota setiap tahunnya mempunyai target dalam penerimaan Pajak Bumi dan Bangunan (PBB) sebagai sumber pendapatan daerah, tetapi tidak selalu target tersebut terealisasi dengan sempurna. Terkadang juga realisasi penerimaan Pajak Bumi dan Bangunan (PBB) jauh dibawah target yang telah ditetapkan oleh Pemerintah Kota.Realisasi Penerimaan Pajak Bumi dan Bangunan di Kota Yogyakarta dapat dilhat pada tabel 1.1.

\section{Tabel 1.1}

\section{Realisasi Penerimaan Pajak Bumi dan Bangunan}

\begin{tabular}{|c|c|c|c|c|c|c|}
\hline \multirow{2}{*}{ Tahun } & \multicolumn{2}{|c|}{ Ketetapan } & \multicolumn{2}{c|}{ Realisasi } & \multicolumn{2}{c|}{ Presentase } \\
\cline { 2 - 7 } & WP & RUPIAH & WP & RUPIAH & WP & RUPIAH \\
\hline 2012 & 90,408 & $45,831,608,230$ & 61,324 & $37,251,111,330$ & 67.83 & 81.28 \\
\hline 2013 & 91,353 & $48,516,909,700$ & 62,161 & $39,387,655,541$ & 64.04 & 81.18 \\
\hline 2014 & 91,832 & $51,735,123,165$ & 58,872 & $39,156,734,983$ & 64.11 & 75.69 \\
\hline
\end{tabular}

Sumber: $\quad$ Dinas Pajak Daerah dan Pengelolaan Keuangan (DPDPK) Kota Yogyakarta

Dari tabel diatas terlihat bahwa presentase wajib pajak yang melaksanakan pembayaran pajak menurun tiap tahun, dimana tahun 2012 terdapat $67,83 \%$ wajib pajak yang membayar kewajiban PBBnya, tahun 2013 64,04\% dan tahun $201464,11 \%$ selain itu, prosentase realisasi pendapatan daerah dari
PBB terhadap ketetapannya menurun drastis di tahun 2014, dimana realisasi PBB tahun $201281,28 \%$, tahun $201381,18 \%$, dan tahun 2014 75,69\%. Data ini menunjukkan bahwa meskipun perhitungan PBB dilakukan secara official asessment system, namun diperlukan kepatuhan dalam pembayarannya. 


\section{Metodologi Penelitian}

a.

ifat Penelitian

Sifat penelitian yang digunakan dalam penelitian ini adalah bersifat kuantitatif yang bertujuan untuk mengetahui apakah ada pengaruh antara pemahaman wajib pajak, kesadaran wajib pajak dan pelayanan fiskus terhadap kepatuhan pajak bumi dan bangunan dan penarikan kesimpulan didasarkan pada angka yang diolah secara statistik. Penelitian ini dilaksanakan di Dinas Pendapatan Daerah (Dispenda) Kota Yogyakarta.

b.

ariabel Penelitian

Variabel penelitian adalah suatu karakteristik, ciri, sifat, watak, milik, atau keadaan yang melekat pada subyek,orang, atau barang ,yang berbeda-beda intesitasnya, banyaknya atau kategorinya (Sigit, 2003). Dalam penelitian ini terdapat dua variabel yaitu variabel dependen dan variabel independen.

Variabel dependen merupakan variabel terikat atau variabel yang dijelaskan dan dipengaruhi oleh variabel independen (Sugiyono, 2011). Variabel dependen yang digunakan dalam penelitian ini adalah kepatuhan wajib pajak. Variabel independen merupakan variabel bebas atau variabel yang mempengaruhi variabel lain (Sugiyono, 2011). Variabel independen dalam penelitian ini meliputi pemahaman wajib pajak, kesadaran wajib pajak, dan pelayanan fiskus. c.

opulasi , Sampel, dan Teknik Pengambilan Sampel

Populasi dalam penelitian ini adalah wajib pajak bumi dan bangunan yang terdaftar pada Dinas Pajak Daerah dan Pengelolaan Keuangan (DPDPK) Kota Yogyakarta. Sampel yang digunakan dalam penelitian ini adalah waijb pajak bumi dan bangunan yang berada di DPDPK Kota Yogyakarta pada tanggal 12 dan 15 januari 2015. Data diperoleh dari kuesioner yang disebar sebanyak 70 kuesioner. Teknik pengambilan sampel dalam penelitian ini menggunkanan convenience sampling (sampling kemudahan). Sampling kemudahan merupakan teknis pengambilan sampel yang diambil secara spontanitas artinya siapa saja yang secara acak tidak sengaja ditemui peneliti dan sesuai dengan karakteristik sampel penelitian maka orang tersebut dapat dijadikan sampel. Dengan kata lain, sampel dipilih karena ada pada tempat dan waktu yang tepat.

d.

umber Data dan Metode Pengumpulan Data Dalam penelitian ini meggunakan data primer. Data primer ini berupa data yang diperoleh dari hasil kuesioner yang diberikan kepada responden. Sumber data primer kuesioner berasal dari wajib pajak bumi dan bangunan yang terdaftar pada Dinas Pajak Daerah dan Pengelolaan Keuangan (DPDPK) Kota Yogyakarta.

Metode pengumpulan data dalam penelitian ini dilakukan dengan menggunakan metode survey melalui angket (kuesioner) untuk mendapatkan data primer dan untuk mendapatkan gambaran umum Dinas Pajak Daerah dan Pengelolaan Keuangan (DPDPK) Kota Yogyakarta yang dilakukan langsung kepada responden. Kuesioner adalah daftar pertanyaan yang diisi oleh responden.

e.

eknik Analisis Data

Analisis dalam penelitian ini menggunakan persamaan regresi linier berganda, alat untuk untuk meramalkan nilai pengaruh dua variabel bebas atau lebih terhadap satu variabel terikat (untuk membuktikan ada tidaknya varißbel bebas XI, X2, $\mathrm{Xn}$.....terhadap suatu variabel $\mathrm{Y}$. Kegunaan dari regresi berganda adalah meramalkan nilai nilai variabel terikat (Y) apabila variabel bebasnya dua atau lebih.

\section{Hasil dan Pembahasan}

\subsection{Karakteristik Responden}

Karakteristik responden dapat dilihat dari demografi responden. Demografi responden merupakan gambaran mengenai responden yang menjadi sampel penelitian. Dalam penelitian ini demografi responden yang digunakan meliputi jenis kelamin, usia, pendidikan, pekerjaan dan pendapatan. 


\section{JURNAL AKUNTANSI VOL.3 NO. 1 JUNI 2015}

Berdasarkan data yang berhasil dikumpulkan responden maka dilihat ringkasan demografi melalui kuesioner yang dibagikan kepada 70 responden sebagai berikut:

\section{Demografi Responden}

\begin{tabular}{cccc}
\hline Data Deskriftif & Keterangan & Jumlah & Prosentase \\
\hline Jenis Kelamin & Laki-laki & 26 & $26 \%$ \\
& Perempuan & 44 & $44 \%$ \\
\hline Usia & 30 tahun & 32 & $32 \%$ \\
& $30-40$ tahun & 11 & $11 \%$ \\
& $>40$ & 27 & $27 \%$ \\
\hline Pendidikan & SD & 1 & $1 \%$ \\
& SMP & 3 & $3 \%$ \\
& SMA & 36 & $36 \%$ \\
& D3 & 8 & $8 \%$ \\
& S1 & 20 & $20 \%$ \\
& S2/S3 & 2 & $40 \%$ \\
& PNS/TNI/POLRI & 40 & $28 \%$ \\
& Swasta & 28 & $2 \%$ \\
\hline Pekerjaan & Mahasiswa & & $64 \%$ \\
& Lain-lain & 2 & $6 \%$ \\
\hline Penghasilan Pertahun & $<50$ juta & 64 & \\
& $50-250$ juta & 6 &
\end{tabular}

Sumber: Data primer diolah 2015

\subsection{Uji Validitas Data dan Realibilitas Data}

Validitas berasal dari validity yang mempunyai arti sejauh mana ketepatan dan kecermatan suatu alat ukur dalm melekukan fungsi ukurnya. Suatu kuesioner dinyatakan valid jika pertanyaan pada kuesioner mampu untuk mengungkapkan sesuatu yang akan diukur oleh kuesioner tersebut (Ghozali, 2011). Uji reabilitas adalah pengujian untuk mengukur suatu kuesioner yang merupakan indikator dari variabel. Suatu kuesioner dikatakan reliabel atau handal jika jawaban seseorang terhadap pertanyaan konsisten atau stabil dari wktu ke waktu. Berikut menunnjukan hasil uji Validitas dan Realibilitas.

\begin{tabular}{|c|c|c|c|c|}
\hline No & Variabel/Indikator & $\begin{array}{l}\mathrm{r} \text { hitung } \\
\text { (Corrected Item } \\
\text { Total } \\
\text { Correlation) }\end{array}$ & r tabel & Keterangan \\
\hline \multirow[t]{9}{*}{1} & Pemahaman Wajib Pajak & & & \\
\hline & butir 2.1 & 0,587 & 0,197 & \\
\hline & butir 2.2 & 0,586 & 0,197 & Valid \\
\hline & butir 2.3 & 0,445 & 0,197 & Valid \\
\hline & butir 2.4 & 0,516 & 0,197 & Valid \\
\hline & butir 2.5 & 0,518 & 0,197 & Valid \\
\hline & butir2.6 & 0,495 & 0,197 & Valid \\
\hline & butir 2.7 & 0,720 & 0,197 & Valid \\
\hline & butir 2.8 & 0,635 & 0,197 & \\
\hline
\end{tabular}


2 Kesadaran Wajib Pajak

\begin{tabular}{llll} 
butir3.1 & 0,423 & 0,197 & Valid \\
butir3.2 & 0,659 & 0,197 & Valid \\
butir3.3 & 0,559 & 0,197 & Valid \\
butir3.4 & 0,520 & 0,197 & Valid \\
butir3.5 & 0,461 & 0,197 & Valid \\
butir3.6 & 0,220 & 0,197 & Valid \\
Pelayanan Fiskus & & & \\
butir4.1 & 0,545 & 0,197 & Valid \\
butir4.2 & 0,349 & 0,197 & Valid \\
butir4.3 & 0,682 & 0,197 & Valid \\
butir4.4 & 0,348 & 0,197 & Valid \\
butir4.5 & 0,575 & 0,197 & Valid \\
butir4.6 & 0,701 & 0,197 & Valid \\
butir4.7 & 0,685 & 0,197 & Valid \\
butir4.8 & 0,522 & 0,197 & Valid \\
\hline
\end{tabular}

Sumber: Data primer diolah 2015

Hasil Pengujian Realibilitas

\begin{tabular}{lcc}
\hline Variabel & Cronbach's Alpha & Keterangan \\
\hline Kepatuhan Wajib Pajak & 0,703 & Realibel \\
Pemahaman Wajib Pajak & 0,829 & Realibel \\
Kesadaran Wajib Pajak & 0,728 & Realibel \\
Pelayanan Fiskus & 0,813 & Realibel \\
\hline
\end{tabular}

Sumber: Data primer diolah 2015

\subsection{Statistik Deskriptif}

Statistik deskriftif variabel-variabel penelitian ini di tampilkan untuk mempermudah dalam mengetahui tanggapan umum responden terhadap variabel-variabel yang diteliti dalam penelitian ini yaitu kepatuhan wajib pajak, pemahaman wajib pajak, kesadaran wajib pajak dan pelayanan fiskus. Variabelvariabel yang digunakan dalam penelitian ini meliputi nilai minimum, maksimum, rata-rata (mean) dan standar deviasi.

Hasil Pengujian Statistik Deskriftif

\begin{tabular}{lccccc}
\hline & $\mathrm{N}$ & Minimum & Maximum & Mean & Std Deviation \\
\hline Kepatuhan wajib pajak & 70 & 24.00 & 40.00 & 317.200 & 375.804 \\
pemahaman wajib pajak & 70 & 18.00 & 30.00 & 253.000 & 276.157 \\
Keasadaran wajib pajak & 70 & 24.00 & 40.00 & 315.800 & 336.404 \\
Pelayanan fiskus & 70 & 11.00 & 30.00 & 234.500 & 371.014 \\
\hline
\end{tabular}

Sumber: Data primer diolah 2015

3.4 Uji Normalitas Data

Uji normalitas bertujuan untuk menguji apakah dalam model regresi, variabel residual memiliki distribusi normal (Ghozali, 2011). Dengan menggunakan analisis grafik terlihat pada gambar 4.1 
bahwa data menyebar disekitar garis diagonal dan mengikuti arah garis diagonal maka pada penelitian ini model regresi memenuhi asumsi normalitas. Berikut adalah tabel hasil pengujian normalitas dengan menggunakan analisis grafik.

Hasil Uji Normalitas

Normal P-P Plot of Regression Standardized Residual

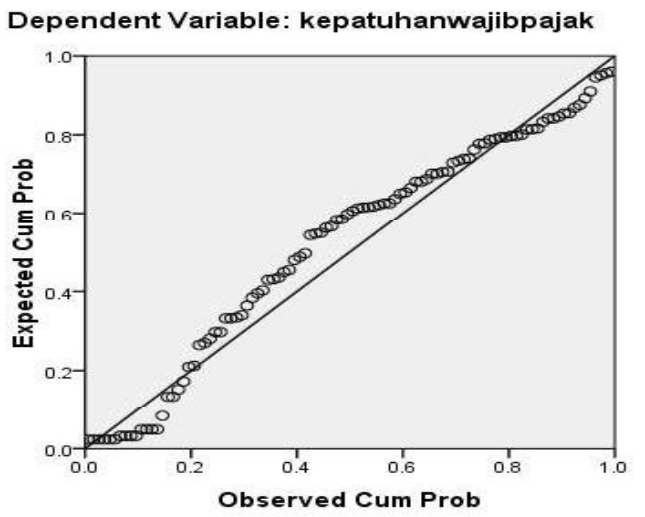

Hasil Uji Normalitas 1-Sample K-S

One-Sample Kolmogorov-Smirnov Test

\begin{tabular}{|c|c|c|}
\hline & & Unstandardized Residual \\
\hline \multicolumn{2}{|l|}{$\mathrm{N}$} & 70 \\
\hline \multirow[t]{2}{*}{ Normal Parameters $^{a}$} & Mean & .0000000 \\
\hline & Std. Deviation & 2.68634772 \\
\hline \multirow{3}{*}{$\begin{array}{l}\text { Most Extreme } \\
\text { Differences }\end{array}$} & Absolute & .124 \\
\hline & Positive & .094 \\
\hline & Negative & -.124 \\
\hline \multicolumn{2}{|l|}{ Kolmogorov-Smirnov Z } & 1.236 \\
\hline \multicolumn{2}{|l|}{ Asymp. Sig. (2-tailed) } & .094 \\
\hline
\end{tabular}

a. Test distribution is Normal.

Sumber: Data primer diolah 2015

Berdasarkan pengolahan data dengan bantuan SPSS 16 data penelitian ini memenuhi normalitas. Hal tersebut

\subsection{Uji multikolonieritas}

Uji multikolonieritas bertujuan untuk menguji apakah dalam model regresi ditemukan adanya korelasi antar variabel bebas (independen). Model regresi yang baik seharusnya tidak terjadi korelasi diantara variabel independen. Jika variabel dibuktikan dengan nilai signifikan lebih besar dari 0,05 yaitu 0,094 .

bebas saling berkorelasi, maka variabelvariabel ini tidak ortogonal. Variabel ortogonal adalah variabel bebas yang nilai korelasi antar sesama variabel bebas sama dengan nol (Ghozali, 2011). Multikolonieritas terjadi jika nilai tolerance di bawah 0,10 dan Variance 
Inflation Factors (VIF) diatas 10 maka dapat diartikan bahwa terdapat multikolonieritas. Sedangkan jika nilai tolerance diatas 0,10 dan VIF di bawah 10 maka tidak terdapat multikolonieritas (Udayana, 2008).

Hasil Uji Multikolonieritas

Coefficients $^{\mathrm{a}}$

\begin{tabular}{llll} 
& \multicolumn{1}{c}{ Model } & \multicolumn{2}{c}{ Collinearity Statistics } \\
\multicolumn{1}{c}{ (Constant) } & Tolerance & VIF \\
\hline & & & \\
& Pemahaman wajib pajak & .590 & 1.695 \\
Kesadaran wajib pajak & .611 & 1.636 \\
& Pelayanan fiskus & .943 & 1.061 \\
\hline
\end{tabular}

a. Dependent Variable: kepatuhan wajib pajak

Sumber: Data primer diolah 2015

Dari Tabel 4.7 di atas dapat dilihat bahwa nilai tolerance semua variabel berada di atas 0,10 dan nilai Variance Inflation Factors (VIF) di bawah 10 sehingga dapat

\subsection{Uji heteroskedastisitas}

Uji heteroskedastisitas bertujuan untuk menguji apakah dalam model regresi terjadi ketidaksamaan variance dari residual satu pengamatan ke pengamatan yang lain. Jika variance dari residual satu pengamatan ke pengamatan yang lain tetap disimpulkan bahwa tidak terjadi Multikolonieritas dalam persamaan regresi berganda.

maka disebut homoskedastisitas dan jika berbeda mak disebut heteroskedastisitas. Model regresi yang baik adalah yang homoskedastisitas atau tidak terjadi heteroskedastisitas (Ghozali, 2011). Berikut hasil grafik scatterplot untuk uji heteroskedastisitas.

Scatterplot

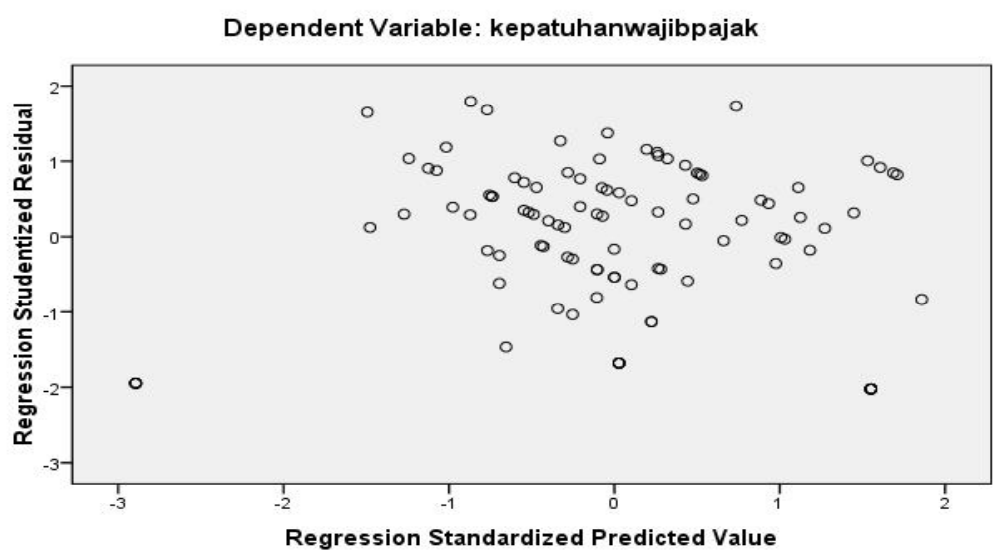

Hasil uji Heteroskedastisitas

Dari grafik diatas, terlihat titik-titk menyebar secara acak, tidak membentuk sebuah pola tertentu yang jelas, serta tersebar baik diatas maupun dibawah 
angka 0 pada sumbu y. Hal ini berarti tidak terjadi heteroskedastisitas pada model regresi. Untuk memperjelas pembacaan gambar 4.12. penelitian ini menggunakan uji glejser. Uji glejser dilakukan dengan meregresi variabel-variabel bebas dalam persamaan regresi dengan nilai residual sebagai variabel terikatnya.

\begin{tabular}{|c|c|c|c|}
\hline \multicolumn{4}{|c|}{$\begin{array}{l}\text { Hasil Uji Glejser } \\
\text { Coefficients }^{\mathbf{a}}\end{array}$} \\
\hline \multicolumn{2}{|r|}{ Model } & \multirow{2}{*}{$\frac{\mathrm{T}}{.247}$} & \multirow{2}{*}{$\begin{array}{l}\text { Sig. } \\
.806\end{array}$} \\
\hline 1 & (Constant) & & \\
\hline & Pemahaman wajib pajak & -1.604 & .112 \\
\hline & Kesadaran wajib pajak & 1.168 & .246 \\
\hline & Pelayanan fiskus & 1.493 & .139 \\
\hline
\end{tabular}

a. Dependent Variable

Sumber: Data primer diolah 2015

Hasil uji Glejser seperti yang terlihat pada Tabel 4.12. diketahui bahwa semua variabel bebas yang digunakan tidak

\subsection{Uji Koefisien Determinasi}

Uji Koefisien Determinasi digunakan untuk mengukur sebarapa besar pengaruh pemahaman wajib pajak, kesadaran wajib berpengaruh secara signifikan terhadap variabel terikat.

pajak dan pelayanan fiskus terhadap kepatuhan wajib pajak. Hasil pengujian dapat dilihat dalam tabel berikut:

Hasil Pengujian Determinasi
Model Summary

Dari tabel 4.13 diketahui bahwa nilai adjusted R square sebesar 0,459 yang berarti bahwa $45,9 \%$ kepatuhan wajib pajak dipengaruhi oleh pemahaman wajib pajak, kesadaran wajib pajak dan pelayanan fiskus. Sedangkan 54,1\% dipengaruhi oleh variabel lain diluar

\subsection{Uji Simultan ( Uji Statistik F)}

Hasil uji ini merupakan pengaruh variabel independen secara simultan terhadap variabel dependen sebagaiman terlihat pada tabel berikut: penelitian.

Hasil Uji Statistik F

\begin{tabular}{lrrcccc}
\hline \multicolumn{1}{l}{ Model } & Sum of Squares & Df & Mean Square & F & Sig. \\
\hline 1 & Regression & 648.320 & 3 & 216.107 & 29.039 & $.000^{\text {a }}$ \\
& Residual & 714.430 & 96 & 7.442 & & \\
Total & 1362.750 & 99 & & & \\
\hline
\end{tabular}


JURNAL AKUNTANSI VOL.3 NO. 1 JUNI 2015

\begin{tabular}{lrrrccc}
\hline \multicolumn{1}{l}{ Model } & Sum of Squares & Df & Mean Square & F & Sig. \\
\hline $1 \quad$ Regression & 648.320 & 3 & 216.107 & 29.039 & $.000^{\text {a }}$ \\
Residual & 714.430 & 96 & 7.442 & & \\
Total & 1362.750 & 99 & & & \\
\hline
\end{tabular}

a. Predictors: (Constant), pelayanan fiskus, kesadaran wajib pajak, pemahaman wajib

pajak

b. Dependent Variable: kepatuhan wajib pajak

Dari uji $\mathrm{F}$ didapat nilai $\mathrm{F}$ hitung sebesar 29.039 dengan probabilitas 0.000 karena probabilitas lebih kecil dari 0.05 maka model regresi dapat digunakan untuk memprediksi kepatuhan wajib pajak (Y).
Ini menunjukkan bahwa pemahaman wajib pajak, kesadaran wajib pajak dan pelayanan fiskus secara simultan berpengaruh terhadap kepatuhan wajib pajak.

\subsection{Uji Parsial ( Uji Statistik t)}

Untuk mengetahui ada tidaknya pengaruh dari masing-masing variabel bebas ini, dimana pemahaman wajib pajak, kesadaran wajib pajak, pelayanan fiskus terhadap variabel terikat kepatuhan wajib pajak maka digunakan uji $\mathrm{t}$ dimana $\mathrm{df}=\mathrm{n}-\mathrm{k}-1=70-3-1=66$, maka $\mathrm{t}$ tabel $=$ 1.668. Hasil uji signifikansi parameter individual (uji statistik t) dapat dilihat pada tabel.

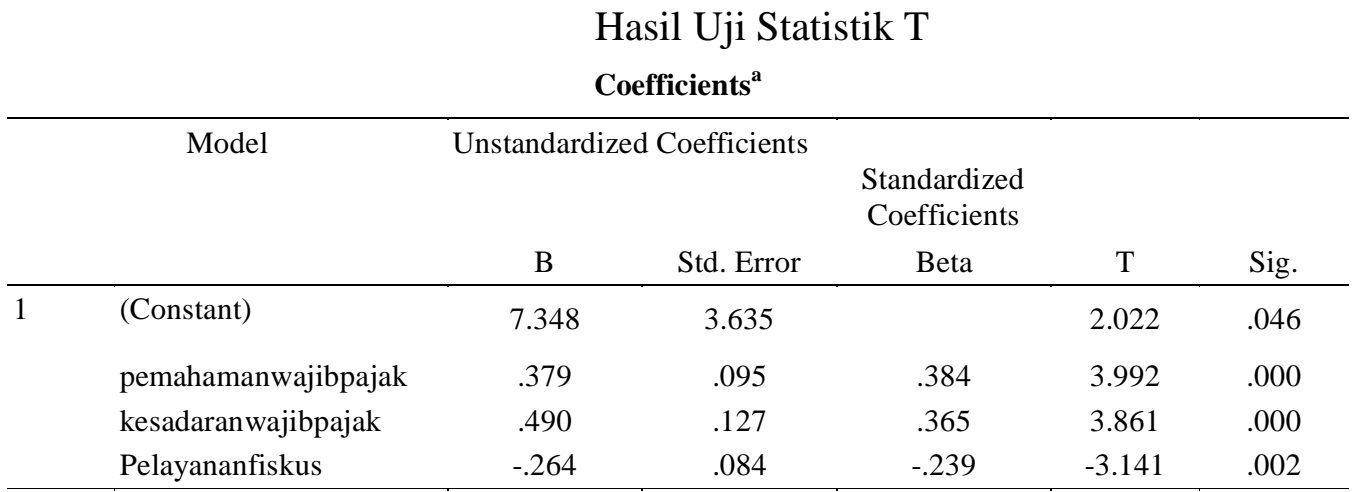

a. Dependent Variable: kepatuhanwajibpajak

Sumber: Data primer diolah 2014

Berdasarkan tabel nilai $\mathrm{t}$ hitung untuk variabel pemahaman wajib pajak (X1) terhadap kepatuhan wajib pajak (Y) 3.992, berarti t hitung $\mathrm{t}$ tabel $(3.992 \quad 1.668)$ memiliki tingkat signifikan 0.000 karena tingkat signifikanya lebih kecil dari 0.05 hal ini membuktikan bahwa $\mathrm{H} 0$ ditolak dan $\mathrm{Ha}$ diterima, ini menunjukkan bahwa variabel pemahaman wajib pajak berpengaruh positif terhadap kepatuhan wajib pajak.

Hasil pengujian variabel kesadaran wajib pajak (X2) terhadap kepatuhan wajib pajak (Y) 3.861, berarti t hitung $>\mathrm{t}$ tabel $(3.861>$ 1.668) memiliki tingkat signifikan 0.000 karena tingkat signifikanya lebih kecil dari 0.05 hal ini membuktikan bahwa H0 ditolak dan Ha diterima, ini menunjukkan bahwa variabel kesadaran wajib pajak berpengaruh positif terhadap kepatuhan wajib pajak.

Hasil pengujian variabel pelayanan fiskus (X3) terhadap kepatuhan wajib pajak (Y) 3.141, berarti $\mathrm{t}$ hitung $<\mathrm{t}$ tabel $(-3.141$ 1.668) memiliki tingkat signifikan 0.002 karena tingkat signifikanya lebih kecil dari 0.05 hal ini membuktikan bahwa H0 diterima dan Ha ditolak, ini menunjukkan bahwa variabel pelayanan fiskus berpengaruh positif terhadap kepatuhan wajib pajak. 


\section{Simpulan}

a. Penelitian ini bertujuan untuk mengetahui pengaruh pemahaman wajib pajak, keasadaran wajib pajak, dan pelayanan fiskus terhadap kepatuhan wajib pajak. Berdasarkan penelitian yang dilakukan pada wajib pajak bumi dan bangunan di Kota Yogyakarata maka dapat diambil kesimpulan bahwa Pemahaman wajib pajak, kesadaran wajib pajak, pelayanan fiskus secara simultan berpengaruh positif terhadap kepatuhan wajib pajak bumi dan bangunan di Kota Yogyakarta.

b. Variabel yang digunakan dalam peneliti dalam penelitian ini hanya tiga variabel independen yaitu pemahaman wajib pajak, kesadaran

\section{Referensi}

Adelina, Rima. 2013. “ Analisis Efektifitas Dan Kontribusi Penerimaan Pajak Bumi Dan Bangunan (PBB) Terhadap Pendapatan Daerah Di Kabupaten Gresik." Universitas Negeri Surabaya.

Ageng, Wahyu Utomo Banyu. 2011. "Jurnal Skripsi. Pengaruh Sikap, Kesadaran Wajib Pajak, dan Pengetahuan Perpajakan Terhadap Kepatuhan Wajib Pajak dalam Membayar Pajak Bumi dan Bangunan di Kecamatan Pamulang Kota Tangerang Selatan." Skripsi S1 Fakultas Ekonomika Dan Bisnis Universitas Islam Negeri Syarif Hidayatullah Jakarta.

Anggraeni, Dian. 2012. "Analisis Strategi Pajak Bumi Dan Bangunan (PBB) Di Kota Surabaya Terhadap Peningkatan Realiasasi Target Penerimaannya Dari Tahun 20062011." Universitas Negeri Surabaya.

Arum, Harjanti Puspa. 2012. "Pengaruh Kesadaran Wajib Pajik, Pelayanan Fiskus dan Sanksi Pajak terhadap Kepatuhan Wajib Pajak Orang Pribadi yang Melakukan Kegiatan Usaha dan Pekerjaan wajib pajak dan pelayanan fiskus, pada penelitian selanjutnya diharapkan dapat menambah variabel independen lainya yang bertujuan untuk mengetahui variabel-variabel lain, seperti pengetahuan perpajakan,sanksi pajak dan sikap wajib pajak yang dapat mempengaruhi variabel dependen yaitu kepatuhan wajib pajak.

c. Penelitian ini hanya di lakukan di Dinas Pajak Daerah dan Pengelolaan Keuangan (DPDPK) Kota Yogyakarta, dengan responden sebanyak 70 , Penelitian selanjutnya dapat menggunakan sampel yang lebih luas agar kesimpulan dapat digeneralisasi.

Bebas (Studi di Wilayah KPP Pratama Cilacap)." Skripsi S1 Fakultas Ekonomika dan Bisnis Universitas Diponegoro Semarang.

Aryobimo, Putut Tri. 2012. "Pengaruh Persepsi Wajib Pajak tentang Kualitas Pelayanan Fiskus terhadap Kepatuhan Wajib Pajak dengan Kondisi Keuangan Wajib Pajak dan Preferensi Risiko sebagai Variabel Moderating (Studi Empiris terhadap Wajib Pajak Orang Pribadi di Kota Semarang)." Skripsi S1 Fakultas Ekonomika Dan Bisnis Universitas Diponegoro Semarang.

Ernawati dan wijaya. 2011. "Pengaruh Pemahaman Akuntansi Pajak terhadap Kepatuhan Wajib Pajak Badan Usaha di Bidang Perdagangan di Kantor Pelayanan Pajak Pratama Banjarmasin." Jurusan Akuntansi Sekolah Tinggi Ilmu Ekonomi Indonesia.

Fikriningrum, Winda Kurnia. 2012. -faktor yang

Mempengaruhi Wajib Pajak Orang Pribadi dalam Memenuhi Kewajiban Membayar Pajak (Studi kasus pada Kantor Pelayanan 
Pajak Pratama Semarang Candisari)." Skripsi S1 Fakultas Ekonomika dan Bisnis Universitas Diponegoro Semarang.

Fuadi, Arabella Oentari dan Yenni Mangoting. 2013. “ Pengaruh Kualitas Pelayanan Petugas Pajak, Sanksi Perpajakan dan Biaya Kepatuhan Pajak Terhadap Kepatuhan Wajib Pajak UMKM." Program Akuntansi Pajak Program Studi Akuntansi Universitas Kristen Petra

Jatmiko, Nugroho Agus 2006. Pengaruh Sikap Wajib Pajak pada Pelaksanaan Sanksi Denda, Pelayanan Fiskus, dan Kesadaran Perpajakan Terhi 67 Kepatuhan Wajib Pajak Studi Em Terhadap Wajib Pajak Orang Pribadi di Kota Semarang. Unisversitas Diponegoro: Tesis Megister Akuntansi.

Jotopurnomo, Cindy dan Yenni Mangoting. 2013. Pengaruh Kesadaran Wajib Pajak, Kualitas Pelayanan Fiskus, Sanksi Perpajakan, Lingkungan Wajib Pajak Berada terhadap Kepatuhan Wajib Pajak Orang Pribadi, Jurnal Tax \& Accounting Review Vol. 1, No.1:50-54.

Mardiasmo. 2002. Akuntansi Sektor Publik. Penerbit Andi. Yogyakarta.

Melindasari, Novita. "Pengaruh Norma Moral, Tingkat Pemahaman, Pemeriksaan, dan Keadilan terhadap Kepatuhan Wajib Pajak Orang Pribadi pada KPP Pratama Tanjungpinang." Jurusan Akuntansi, Fakultas Ekonomi, Universitas Maritim Raja Ali Haji, Tanjungpinang.

Muliari dan Setiawan. 2011. "Pengaruh Persepsi tentang Sanksi Perpajakan dan Kesadaran Wajib Pajak pada Kepatuhan Pelaporan Wajib Pajaka Orang Pribadi di Kantor Pelayanan Pajak Prataman Denpasar Timur." Skripsi S1 Jurusan Akuntansi Fakultas Ekonomi Universitas Udayana.
Muqodim. 1999. Perpajakan, Buku Satu, Edisi 2, Yogyakarta: UII Press.

Mutia, Sri Putri Tita. 2014. "Pengaruh Sanksi Perpajakan, Kesadaran Perpajakan, Pelayanan Fiskus, dan Tingkat Pemahaman Terhadap Kepatuhan Wajib Pajak Orang Pribadi (Studi Empiris pada Wajib Pajak Orang Pribadi yang terdaftar di KPP Pratama Padang)." Fakultas Ekonomi Universitas Negeri Padang.

Nafilah. 2013. "Intenisfikasi Pemungutan Pajak Bumi dan Bangunan di Dinas Pendapatan Daerah Kota Makassar." Skripsi S1 Fakultas Ilmu Sosial dan Ilmu Politik Universitas Hasanuddin.

Peraturan Menteri Keuangan dan Menteri Dalam Negeri Nomor: 213/PMK.07/2010, Nomor: 58 Tahun 2010 tentang Tahapan Persiapan Pengalihan Pajak Bumi dan Bangunan Perdesaan dan Perkotaan sebagai Pajak Daerah.

Permatasari, Aprilia dan Yaniartha. 2012. "Pengaruh Kesadaran Wajib Pajak dan Sanksi Perpajakan pada Kepatuhan Wajib Pajak dalam Membyar Pajak Bumi dan Bangunan." Fakultas Ekonomi Universitas Udayana.

Pranadata, I Gede Putu. 2014. "Pengaruh Pemahaman Wajib Pajak, Kualitas Pelayanan Perpajakan, dan Pelaksanaan Sanksi Pajak, terhadap Kepatuhan Wajib Pajak Orang Pribadi pada KPP Pratama Batu." Fakultas Ekonomi dan Bisnis Universitas Brawijaya Malang.

Pratiwi dan Setiawan. 2014. "Pengaruh Kesadaran Wajib Pajak, Kualitas Pelayanan, Kondisi Keuangan Perusahaan, dan Persepsi Tentang Sanksi Perpajakan pada Kepatuhan Wajib Pajak Reklame di Dinas Pendapatan Kota Denpasar." Fakultas Ekonomi dan Bisnis Universitas Udayana.

Rahman, Abdul. 2011. "Intensifikasi Pemungutan Pajak Bumi dan Bangunan di 
JURNAL AKUNTANSI VOL.3 NO. 1 JUNI 2015

Kecamatan Soreang Kota Pare-Pare." Jurusan Ilmu Administrasi, Fakultas Ilmu Sosial dan Ilmu Politik Universitas Hasanuddin.

Siddiq, Muhammad. 2011. "Faktor-Faktor yang Mempengaruhi Kesadaran Wajib
Pajak dalam Membayar Pajak Bumi dan Skripsi

S1 Fakultas Ekonomika Dan Bisnis Universitas Islam Negeri Syarif Hidayatullah Jakarta 